\title{
Neurocognitive impact of Zika virus infection in adult rhesus macaques
}

\author{
Denise C. Hsu ${ }^{1,2,3 *} \mathbb{D}$, Kesara Chumpolkulwong², Michael J. Corley ${ }^{4}$, Taweewun Hunsawong ${ }^{2}$,
} Dutsadee Inthawong ${ }^{2}$, Alexandra Schuetz ${ }^{1,2,3}$, Rawiwan Imerbsin², Decha Silsorn², Panupat Nadee², Jumpol Sopanaporn², Yuwadee Phuang-Ngern², Chonticha Klungthong ${ }^{2}$, Matthew Reed ${ }^{2}$, Stefan Fernandez², Lishomwa C. Ndhlovu ${ }^{4,5}$, Robert Paul ${ }^{6}$, Luis Lugo-Roman², Nelson L. Michael ${ }^{7}$, Kayvon Modjarrad ${ }^{8 \dagger}$ and Sandhya Vasan ${ }^{1,3,8+}$

\begin{abstract}
Background: Zika virus (ZIKV) is a mosquito-transmitted flavivirus that affects many regions of the world. Infection, in utero, causes microcephaly and later developmental and neurologic impairments. The impact of ZIKV infection on neurocognition in adults has not been well described. The objective of the study was to assess the neurocognitive impact of ZIKV infection in adult rhesus macaques.

Methods: Neurocognitive assessments were performed using the Cambridge Neuropsychological Test Automated Battery (CANTAB) via a touch screen and modified Brinkman Board before and after subcutaneous ZIKV inoculation. Immune activation markers were measured in the blood and cerebral spinal fluid (CSF) by multiplex assay and flow cytometry.
\end{abstract}

Results: All animals $(N=8)$ had detectable $Z$ IKV RNA in plasma at day 1 post-inoculation (PI) that peaked at day 2 PI (median 5.9, IQR 5.6-6.2 $\log _{10}$ genome equivalents $/ \mathrm{mL}$ ). In all eight animals, ZIKV RNA became undetectable in plasma by day 14 PI, but persisted in lymphoid tissues. ZIKV RNA was not detected in the CSF supernatant at days 4, 8, 14 and $28 \mathrm{PI}$ but was detected in the brain of 2 animals at days 8 and $28 \mathrm{PI}$. Elevations in markers of immune activation in the blood and CSF were accompanied by a reduction in accuracy and reaction speed on the CANTAB in the majority of animals.

Conclusions: The co-occurrence of systemic and CSF immune perturbations and neurocognitive impairment establishes this model as useful for studying the impact of neuroinflammation on neurobehavior in rhesus macaques, as it pertains to ZIKV infection and potentially other pathogens.

Keywords: Zika virus, Neurocognition, Neurobehavior, Neuro-inflammation

\section{Introduction}

Zika virus (ZIKV) is a mosquito-borne pathogen of the Flaviviridae family of single-stranded positive RNA viruses, which includes Dengue virus (DENV), Yellow

\footnotetext{
*Correspondence: dehsu@hivresearch.org

${ }^{\dagger}$ Kayvon Modjarrad and Sandhya Vasan contributed equally to this work

1 US Military HIV Research Program, Walter Reed Army Institute of Research, Silver Spring, MD 20910, USA

Full list of author information is available at the end of the article
}

fever virus (YFV), Japanese encephalitis virus (JEV), West Nile virus (WNV) and tick-borne encephalitis virus (TBEV) [1]. At the height of the 2016 public health emergency, over 8000 cases of ZIKV infection were reported per week in Brazil. By that point, over 8604 babies had been born with a constellation of congenital malformations that eventually became known as congenital Zika syndrome $[2,3]$. original author(s) and the source, provide a link to the Creative Commons licence, and indicate if changes were made. The images or other third party material in this article are included in the article's Creative Commons licence, unless indicated otherwise in a credit line to the material. If material is not included in the article's Creative Commons licence and your intended use is not permitted by statutory regulation or exceeds the permitted use, you will need to obtain permission directly from the copyright holder. To view a copy of this licence, visit http://creativecommons.org/licenses/by/4.0/. The Creative Commons Public Domain Dedication waiver (http://creativeco mmons.org/publicdomain/zero/1.0/) applies to the data made available in this article, unless otherwise stated in a credit line to the data. 
The outbreak in the Western hemisphere revealed that ZIKV is highly neurotropic, as it was repeatedly isolated from brain tissue [4-6]. ZIKV has also been demonstrated to infect human neural progenitor cells, attenuating their growth and accelerating cell death $[7,8]$. In utero infection is associated with microcephaly and other congenital malformations [9-11]. Furthermore, infants seemingly asymptomatic at birth may eventually develop abnormalities detected by brain imaging or in subsequent neurodevelopmental evaluations [12-15]. In adults, ZIKV infection is generally asymptomatic, manifesting in $20 \%$ as a syndrome of maculo-papular rash, fever, conjunctivitis, arthralgia, myalgia and headache [16-19]. Guillain-Barré syndrome [11,20,21] and encephalitis [22] have also been reported. The differential impact of ZIKV on the CNS in fetal vs adult infection is likely because undifferentiated neurons during the early stages of neurogenesis in fetal brains, are highly permissive to ZIKV infection, whereas differentiated neurons, representative of adult brain neurons, are relatively resistant to the virus [23]. In one case study of a ZIKV-infected adolescent, neurocognitive changes (including slow processing speed, impaired visuospatial learning and memory) persisted for more than 4 months post-infection [24]. Otherwise, the impact of ZIKV infection on adult neurocognition has not been well described.

Nonhuman primate (NHP) models are useful in the study of viral neuropathogenesis as they are closely related to humans, especially with respect to brain pathology, which is typically difficult to investigate in humans. Furthermore, NHPs are highly permissive to infection by ZIKV and pathogenesis mimics that in humans [25]. Studies of ZIKV in NHPs were first reported in 1952 by Dick et al., who noted the neurotropism of ZIKV in mice and demonstrated intracerebral inoculation of monkeys resulting in viremia [26]. Subsequent studies of ZIKV neuropathogenesis in NHPs have mostly focused on in utero infection [27, 28]. Loss of brain volume and neuronal progenitor cells, gliosis and hippocampal injuries have been shown [27-29]. A study of postnatal infection at 5 weeks after birth found ZIKV RNA and inflammatory infiltrates in the central nervous system. Structural abnormalities were also evident on magnetic resonance imaging at 3-6 months post-infection. Furthermore, ZIKV-infected animals displayed reduced hostility and anxiety behaviors than controls during a stress-induction paradigm [30].

There remains a knowledge gap in the impact of ZIKV infection on adult neurocognition. In this study, we assessed the impact of ZIKV on neurocognition in adult infection in rhesus macaques using the Cambridge Neuropsychological Test Automated Battery (CANTAB, $[31,32])$ system for NHPs and a fine motor speed and dexterity task modeled from the Brinkman Task [33]. The CANTAB system for NHPs contains a series of computerized tests of memory, attention and executive function that is administered through a touch-sensitive screen linked to a food reward dispenser. It has been developed and validated for the assessment of neurocognitive deficits in both animals and humans [34, 35]. We sought to correlate immune and neurobehavioral findings to model the impact of ZIKV infection on CNS function in adult rhesus macaques.

\section{Methods}

\section{Animal selection}

Animals were housed at the AAALAC Internationalaccredited, Armed Forces Research Institute of Medical Sciences (AFRIMS) in Bangkok, Thailand. The protocol was approved by the AFRIMS Institutional Animal Care and Use Committee. Research was conducted in compliance with Thai laws, the Animal Welfare Act and other U.S. federal statutes and regulations relating to animals and experiments involving animals and adheres to principles stated in the Guide for the Care and Use of Laboratory Animals, 2011 edition [36].

\section{Study design}

Eight adult, Indian-origin rhesus macaques (Macaca mulatta, 4 males, 4 females), median age 6 (range 5-7) years, median weight 8.2 (range 5.8-10.3) $\mathrm{kg}$ were included in the study. Prior to entry into the study, animals were screened to confirm normal physical condition, complete blood count, blood chemistry and sero-negativity to mosquito-borne Flaviviruses endemic to Thailand, including DENV (serotypes 1, 2, 3 and 4), JEV and ZIKV. Animals were trained to undergo neurocognitive assessment for 24 weeks prior to ZIKV inoculation at day 0 . Animals were then divided into two groups and were humanely euthanized early (day $8 \mathrm{PI}, n=4$ ) or late (day $28 \mathrm{PI}, n=4$ ). In both groups, plasma ZIKV RNA was monitored daily for 6 days PI. Animals in the late group also underwent CSF collection at days 4, 14 and during necropsy and lymph node collection at day 4 and during necropsy (Fig. 1A). Characteristics of the animals including age, sex, weight and group assignment are listed in Fig. 1B.

\section{NHP CANTAB training and assessment}

The Monkey CANTAB Intellistation with Pellet Reward (Lafayette Instrument, Lafayette, IN, USA) was used to perform neurocognitive testing. In this study, rhesus macaques were assessed using the Motor Screening Task (MOT) and Self-Ordered Spatial Search (SOSS). The MOT assesses sensorimotor deficits and reaction speed. The SOSS assesses frontal lobe working memory 


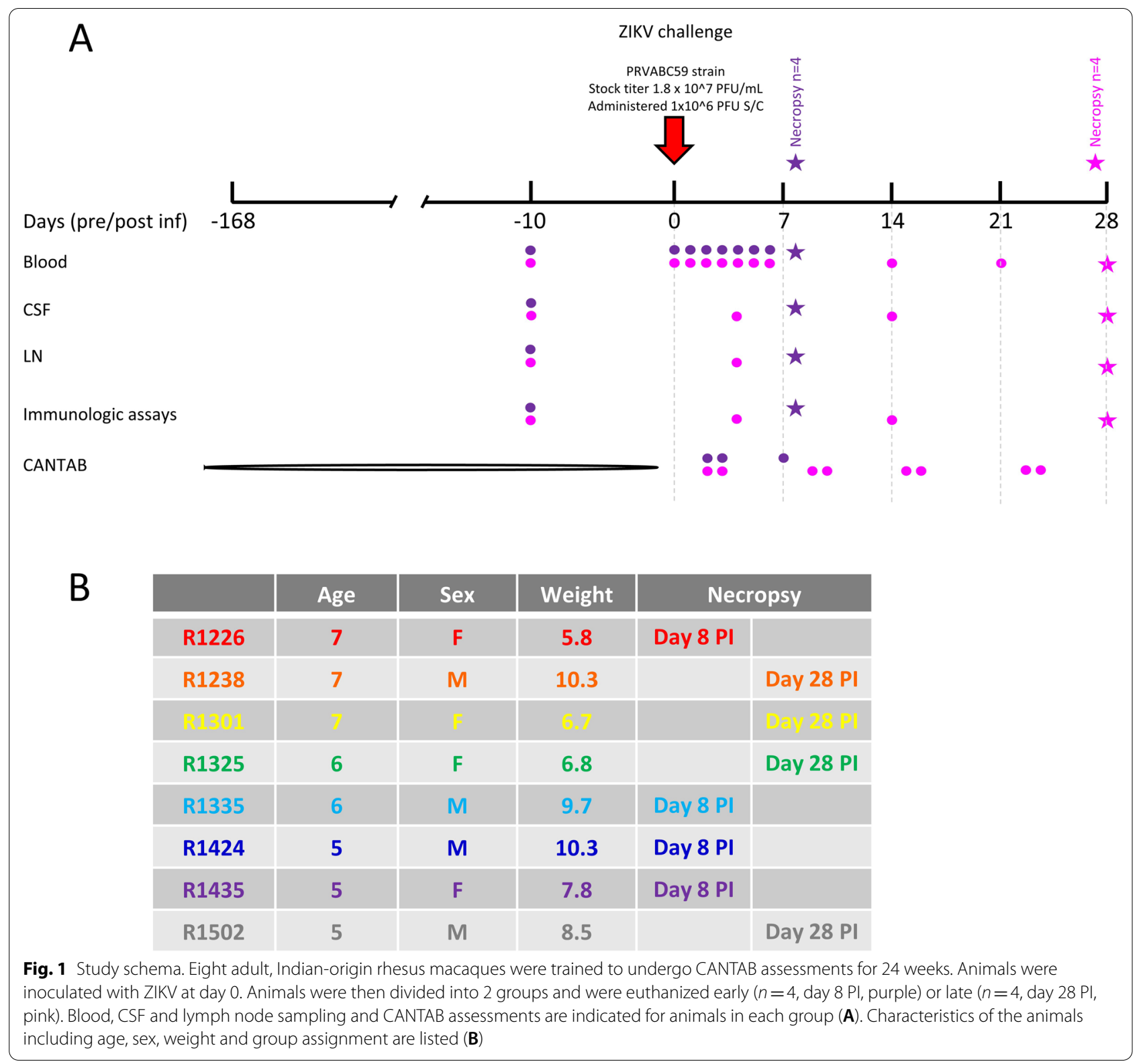

functions. Both of these tests have been widely used in humans and monkeys, across a range of ages [35, 37-40] and pathological conditions, including neurodegenerative [41, 42], neuropsychiatric [43], infectious [44, 45] and the effects of psychotropic agents [46-49].

The animals were trained to undergo CANTAB assessments 2-3 times a week, in 5-25 min afternoon sessions, for 24 weeks (Additional file 1: Fig. S1). Step 1: To familiarize the animal, CANTAB Intellistation was brought in front of the animal's cage and the animal was allowed to explore it and take rewards from the dispenser in response to an auditory stimulus from a manual clicker. Step 2: A visual stimulus, filling the whole screen was presented and the animal was rewarded for touching the screen. Step 3: The visual stimulus reduced in size iteratively following 10 consecutive correct responses. The animal was rewarded after each correct response. Step 4 (Motor Screening Task, MOT): A colored stimulus of fixed-size appeared on the screen in random locations and the animal received a reward after touching the stimulus. Animals were given $10 \mathrm{~min}$ to complete as many motor tasks as possible. Accuracy on the motor task was calculated as the percentage of correct responses divided by the total responses; and speed was determined by the number of tasks the animal was able to complete within 10 min. Step 5 (Self-Ordered Spatial Search, SOSS): A set 
of visual stimuli were presented together at the start of each individual trial. The animal was required to touch each stimulus without returning to a stimulus already selected. Trials were defined as completed when the animal either touched all of the targets without repetition (correct), touched a target that had previously been selected in that trial (error), or failed to touch a target within $30 \mathrm{~s}$ (omission). After an inter-trial interval of 5 or more seconds, a new trial was presented with stimuli randomly assigned to a new location on the screen. A blank screen was presented briefly after each response. Animals were required to complete 40 SOSS tasks. Accuracy on SOSS was calculated as the percentage of correct responses divided by the total responses; and speed was determined by the time taken to complete 40 tasks.

Sex differences were observed in the rate of learning between male and female animals for SOSS training and, thus, required a shift in the presentation of tasks and rewards to motivate the female animals.

\section{Modified Brinkman Board}

This task assessed fine motor speed and dexterity. It involved the retrieval of raisins from a board that contained wells oriented in different directions (i.e., vertically, horizontally and diagonally) with different depths and angles [33, 50,51]. The task was administered using two boards that differed in task complexity vis-à-vis increasing the depth of wells, altering the angle of the wells and increasing the number of wells (from 6 wells on the first board to 9 wells on the second board). Animals were assessed once pre-infection and twice per week post-infection, on the same day as the CANTAB assessment. The dependent variables included the number of raisins retrieved and the time taken to clear the board of raisins.

\section{Assays to screen for DENV, JE and ZIKV sero-positivity} Hemagglutination inhibition (HAI) assays were used to screen for flavivirus sero-positivity by measuring of DENV1-4, JEV and ZIKV antibodies in serum collected 2 weeks prior to study entry. Serum was heat inactivated at $56{ }^{\circ} \mathrm{C}$ for $30 \mathrm{~min}$ and non-specific protein binding was reduced by acetone extraction. Two-fold serially diluted serum samples were added to individual sucrose-acetone extracted viral antigens. Hemagglutination was detected by the addition of goose red blood cells. HAI titer was defined as the highest dilution of serum that inhibited hemagglutination. Only NHPs with HAI titer $<10$ for all viral antigens were included in this study.

\section{Verification of infectious ZIKV by plaque assay}

Infectious ZIKV was quantified by plaque assay using LLC-MK2 cell. Viral supernatant was ten-fold serial diluted, starting from 1:10 to 1:10,000, with tissue culture media, Minimum Essential Media (MEM) supplemented with $10 \%$ heat inactivated FBS (Invitrogen, USA). Then, $100 \mu \mathrm{L}$ of diluted sample was added onto triplicate wells of LLC-MK2 cell monolayer in 12-well plates. After incubation for $1 \mathrm{~h}$ at room temperature (RT) on a rocker platform, the excess amount of inoculum was removed. First overlay medium with 1.8\% LMP was added and the agar was allowed to solidify at RT prior to incubation at $35^{\circ} \mathrm{C}$, $5 \% \mathrm{CO}_{2}$ for 4 days. Virus-infected cells or plaque forming units (PFU) were visualized after staining with second overlay medium containing $4 \%$ Neutral red (Sigma, USA) on the following day. The average number of plaque from triplicate wells in each dilution was used to calculate ZIKV titer per milliliter (PFU/mL).

\section{Zika virus challenge}

ZIKV PRVABC59 strain (stock titer of $1.8 \times 10^{7} \mathrm{PFU} /$ $\mathrm{mL}$, provided by R. De La Barrera, WRAIR) was used [52]. Animals were inoculated with $1 \times 10^{6} \mathrm{PFU}$ subcutaneously in the left leg at week 0 . Animals were observed three times per day for clinical signs of disease including inappetence, dehydration and lethargy. Intra-rectal temperature was measured daily using pole collar chair restraint for 10 days after ZIKV inoculation.

\section{Quantitation of ZIKV RNA}

Plasma, CSF and tissue ZIKV-RNA levels were measured using real-time quantitative PCR [53, 54]. Viral RNA was extracted from $140 \mu \mathrm{L}$ plasma and CSF using the QIAamp viral RNA mini kit (QIAGEN, Germany). For tissue samples, RNeasy Mini Kit (QIAGEN, Germany) was used as per the manufacturer's instruction. ZIKV real-time quantitative RT-PCR was performed using a method modified from Lanciotti et al. [55]. Two primer/ probe sets were used: (1) ZIKV 1086 forward, ZIKV 1162c reverse primers and ZIKV 1107-FAM probe [56]; and (2) ZIKV 4434 forward, ZIKV 4524c reverse primes and ZIKV 4479c-FAM probe [57]. In each experiment, 3 internal controls (no template control, NTC, negative extraction control, NEC and positive extraction control, PCE) and 6 in vitro transcribed RNA standards (at 5, 50, $5 \times 10^{2}, 5 \times 10^{3}, 5 \times 10^{4}, 5 \times 10^{5}$ copies/reaction) were included. All assays were performed using the SuperScript III Platinum One-Step Quantitative RT-PCR kit (Invitrogen), as per manufacturer's instructions, using the Applied Biosystems 7500 Fast Real-Time PCR systems (Life Technologies). Limit of quantification of the assay was 5 copies. The amount of ZIKV in GE/mL in controls and samples were calculated using the formula $\mathrm{GE} / \mathrm{ml}=$ (copies per reaction $\mathrm{x}$ eluted $\mathrm{RNA}$ vol $\times 1000$ $\mathrm{ul}$ )/ (RNA vol used in the reaction (ul) $x$ serum vol used $(\mathrm{ul})$ ). 


\section{Measurement of plasma and CSF cytokine levels}

Plasma and CSF soluble markers of immune activation (including G-CSF, GM-CSF, IFN $\gamma$, IL-1 $\beta$, IL-1ra, IL-2, IL-4, IL-5, IL-6, IL-8, IL-10, IL-12/23(p40), IL-13, IL-15, IL-17A, MCP-1, MIP-1 $\beta$, MIP-1 $\alpha$, SCD40L, TGF- $\alpha$, TNF- $\alpha$, VEGF, and IL-18) were quantified using the MILLIPLEX MAP Non-Human Primate Cytokine Magnetic Bead Panel (EMD Millipore Corporation, Billerica, Massachusetts, USA) as per manufacturer instructions, as previously described [58].

\section{Flow cytometric assessments of $\mathrm{T}$ cell activation}

Immunophenotyping was performed on freshly isolated peripheral blood mononuclear cells (PBMC) using Ficoll Separation Medium, Histopaque ${ }^{\circledR}-10771$ (Sigma-Aldrich, St. Louis, MO, USA), before resuspension in Dulbecco's Phosphate Buffered Saline (DPBS; Life Technologies, Paisley, UK). Fresh cerebrospinal fluid (CSF) was centrifuged at $400 g$ at $4{ }^{\circ} \mathrm{C}$ for $10 \mathrm{~min}$. CSF cell pellet was washed with DPBS and used for immunophenotyping.

Cells were stained with Aqua Live/Dead dye (Invitrogen, Eugene, OR, USA) in the presence of $10 \%$ mouse IgG (Fc block; Invitrogen, Eugene, OR, USA). Subsequently samples were stained for $20 \mathrm{~min}$ at $4{ }^{\circ} \mathrm{C}$ with the following antibodies: anti-CD3 PE-CF594 (BD Horizon, San Diego, CA, USA), anti-CD4 Pacific Blue (Biolegend, San Diego, CA, USA), anti-CD8 BV785 (Biolegend, San Diego, CA, USA), anti-CD19 BV605 (Biolegend, San Diego, CA, USA), anti-CD20 BV711 (Biolegend, San Diego, CA, USA), anti-CD16 PE-Cy5 (Biolegend, San Diego, CA, USA), anti-CD56 PE-Cy7 (BD Bioscience, San Jose, CA, USA), anti-CD14 BV650 (BD Horizon, San Diego, CA, USA), anti-CD38 PE (Caprico Biotechnologies, Norcross, GA, USA), and anti-HLA-DR APC-H7 (BD Pharmingen, San Diego, CA, USA). They were then permeabilized with 1X BD Perm/Wash buffer (BD Bioscience, San Jose, CA, USA) for 15 min at $4{ }^{\circ} \mathrm{C}$ before staining with anti-Ki67 AlexaFluor488 (BD Pharmingen, San Diego, CA, USA) for $30 \mathrm{~min}$ at $4{ }^{\circ} \mathrm{C}$. After staining cells were resuspended in $1 \%$ formaldehyde and acquired immediately using a custom-built LSRFortessa flow cytometer (BD, San Jose, CA, USA) and analyzed using FlowJo software version 10.5.3 or higher (TreeStar, Ashland, OR, USA).

\section{Histopathology}

Tissue samples were fixed in $4 \%$ paraformaldehyde for 16-24 $\mathrm{h}$, processed in an automatic tissue processor (TP1020; Leica, Buffalo Grove, IL, USA), paraffin embedded, sectioned at $5 \mathrm{um}$, and mounted onto adhesive microscope slides (BioGnost, Medugorska, Zagreb, Croatia).

Slides were stained with Harris's hematoxylin solution (In-House Prep.) for $10 \mathrm{~min}$, washed and stained with Eosin solution (In-House Prep.) for $45 \mathrm{~s}$, dehydrated with ethanol, and cleared with xylene prior to mounting with toluene-based mounting medium (Thermo Fisher Scientific, Kalamazoo, MI, USA).

Slides from basal ganglia and parietal areas of the brain were reviewed by a board-certified veterinary pathologist, in comparison to similar tissue sections from control animals.

\section{Statistical analyses}

Analysis of virologic and immunologic data was performed using GraphPad Prism v8.4.3 (GraphPad Software). Comparisons between different time-points in the same animals were performed using Wilcoxon matchedpairs signed rank test. Pre-infection CANTAB performance was established by generating mean and standard deviation (SD) using the last 4 sessions of assessment prior to ZIKV inoculation (Additional file 2: Table S1). To quantify changes post-infection, individualized Z-scores (number of SD below or above the pre-infection mean) were generated using data from each animal post-ZIKV inoculation. This method of quantification of neurocognitive impairment was based on the work of Weed et al. [44] and is advantageous as it takes into account individual variability in performance in each animal preand post-infection. Impairment was defined as $>2.5 \mathrm{SD}$ (corresponded to 99\% confidence interval around the baseline mean) reduction in accuracy for both MOT and SOSS, $>2.5 \mathrm{SD}$ reduction in the number of MOT performed within $10 \mathrm{~min}$ or $>2.5 \mathrm{SD}$ increase in time to complete 40 SOSS tasks.

\section{Results}

Clinical evaluations of ZIKV-inoculated rhesus macaques

Eight rhesus macaques were infected with ZIKV through subcutaneous ZIKV inoculation. Apart from transient reduction in appetite, animals did not exhibit any signs of clinical illness including fever (intra-rectal temperature $>103^{\circ} \mathrm{F}$ ).

\section{ZIKV RNA was detectable in plasma and lymph node tissues in all animals post-infection}

All animals had detectable ZIKV RNA in their plasma at day 1 PI that peaked at day 2 PI (median $7.55 \times 10^{5}$, IQR $4.1 \times 10^{5}-1.69 \times 10^{6}, \mathrm{GE} / \mathrm{mL}$ ). Plasma ZIKV RNA declined rapidly and became undetectable in plasma by day $8 \mathrm{PI}$ in all animals in the Early group and day 14 in all animals in the Late group (Fig. 2A). ZIKV RNA was detectable in lymph node tissues in 4 of 4 animals 
A

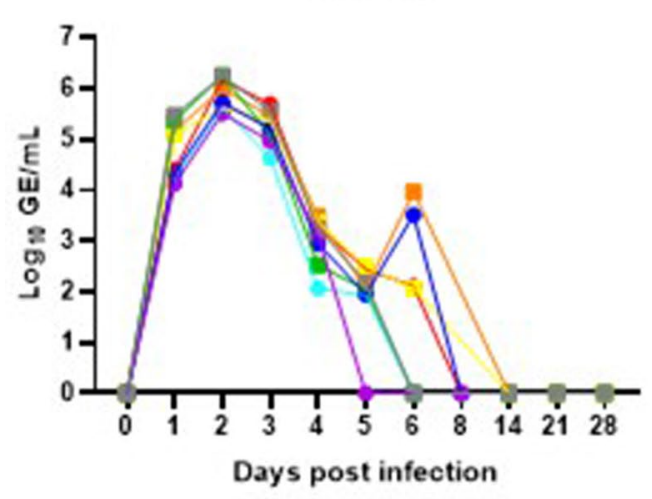

B

\section{CSF and Lymph Node ZIKV RNA}

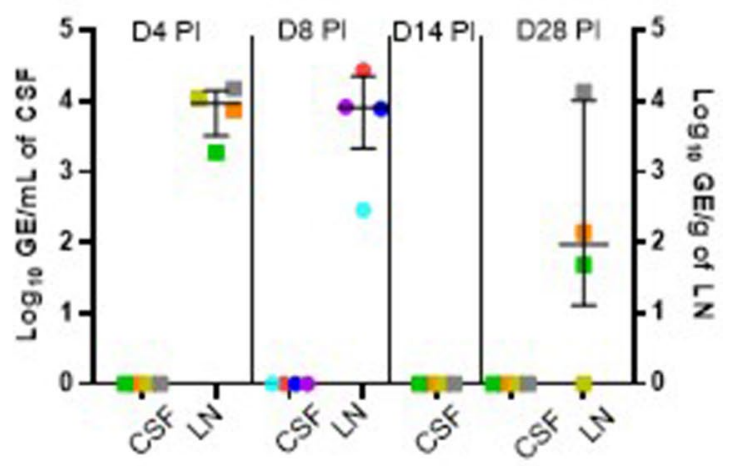

C

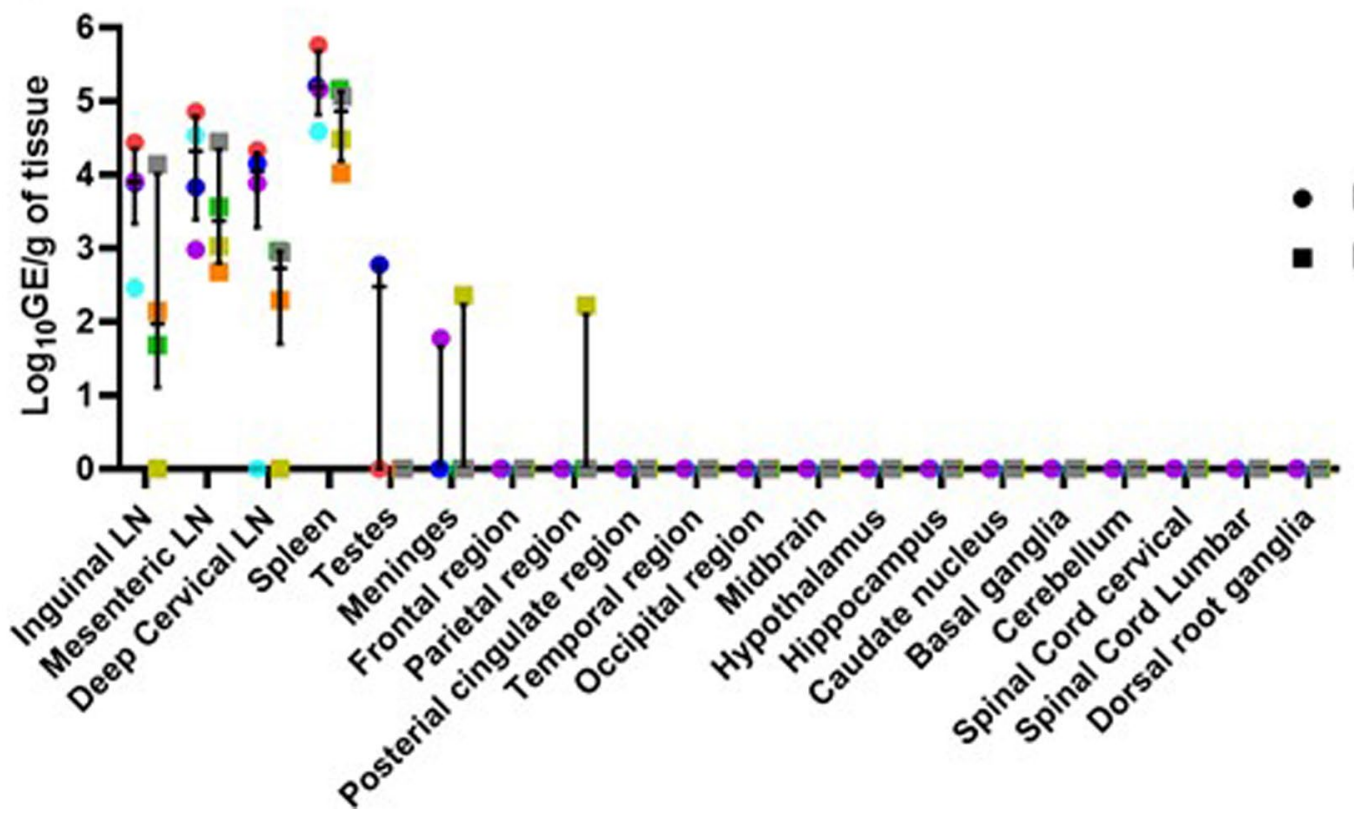

Fig. 2 ZIKV RNA levels. All animals had detectable ZIKV RNA in plasma at day 1 post-inoculation (PI) that peaked at day 2 PI and became undetectable in plasma by day 14 in all animals (A). ZIKV RNA was not detected in the CSF in the time points sampled (B). ZIKV RNA was detected in the central nervous system in 2 animals and in lymph node tissues in all animals at the time of necropsy (C). Each color represents data from individual animals as listed in Fig. 1B, animals in the early group are represented by circles and the late group by squares

at day 4 (Late group) and at day 8 (Early group) and persisted in 3 of 4 animals (Late group) at day $28 \mathrm{PI}$ (Fig. 2B). ZIKV RNA was not detected in CSF supernatant at any of the time points measured (day 8 in $n=4$ Early group, days 4,14 and 28 in $n=4$, Late group, Fig. 2B). Of the 15 different areas of the nervous system assessed (Fig. 2C), only low levels of ZIKV RNA were detected in the meninges (R1301 at $228 \mathrm{GE} / \mathrm{mg}$ at day $28 \mathrm{PI}$ and R1435 at $60 \mathrm{GE} / \mathrm{mg}$ at day $8 \mathrm{PI})$ and the parietal region (R1301 at $166 \mathrm{GE} / \mathrm{mg}$ at day $28 \mathrm{PI})$.

\section{Transient immune activation in the peripheral blood} and CSF

Significant increases in a number of soluble markers of immune activation including IL-15 $(p=0.0078)$, MCP-1 $(p=0.0156)$, IL-1 RA $(p=0.0156)$, and IL-2 $(p=0.0078)$ were observed in plasma at day $4 \mathrm{PI}$ (Fig. 3), that then reduced and normalized by day 14 PI. Similar trends were observed in the CSF and were statistically significant for IL-15 $(p=0.0156)$, MCP-1 $(p=0.0156)$ and G-CSF $(p=0.0391)$ when results from 

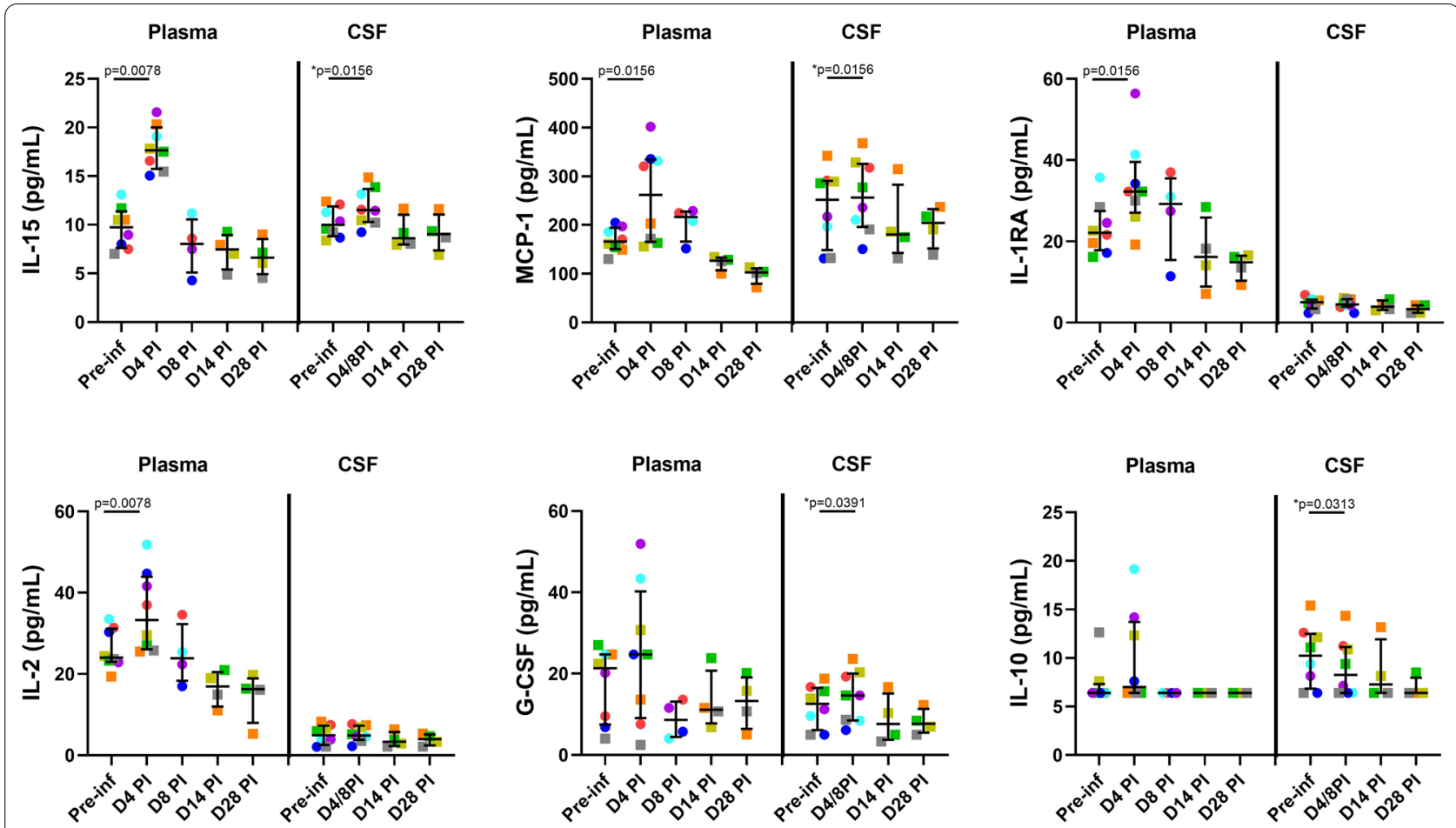

Fig. 3 Plasma and CSF soluble markers of immune activation. Transient increases in soluble markers of immune activation were observed in the plasma (interleukin, IL-15, monocyte chemoattractant protein-1, MCP-1, IL-1 receptor antagonist, IL-1RA and IL-2) and CSF (IL-15, MCP-1, granulocyte colony stimulating factor, G-CSF) early post-ZIKV infection. Each color represents data from individual animals as listed in Fig. 1B. * $P$ values for CSF comparisons were based on early post-inoculation (PI) results from all 8 animals (Late group, $n=4$ at day $4 \mathrm{Pl}$, squares and Early group, $n=4$ at day $8 \mathrm{Pl}$, circles)

animals in the Early $(n=4$, day $8 \mathrm{PI})$ and Late $(n=4$, day 4 PI) groups were combined (Fig. 3). Levels normalized by day 14 PI. In addition, a pattern of reduction in CSF IL-10 levels was also seen post-infection (Fig. 3). When compared to pre-infection, significant increases in cellular markers of immune activation were also identified in CD4 $(\mathrm{Ki} 67+, p=0.0156$ and CD38 + HLA-DR +, $p=0.0156$, Fig. 4A, B) and CD8 $(\mathrm{Ki} 67+, p=0.0234$, Fig. $4 \mathrm{C}) \mathrm{T}$ cells in the peripheral blood and in CD8 (CD38+HLA-DR,$+ p=0.0078$ ) $\mathrm{T}$ cells in the CSF (Fig. 4D), when data from animals in the Early $(n=4$, day $8 \mathrm{PI})$ and Late $(n=4$, day $4 \mathrm{PI})$ groups were combined. Interestingly, CD4 and CD8 T cell activation mostly resolved in the peripheral blood by day 14 PI but CSF CD38 + HLA-DR + CD8 T cell frequency peaked at day $14 \mathrm{PI}$ and remained elevated in 2 of 4 animals (when compared to each animals' pre-infection level) at day $28 \mathrm{PI}$. Thus, ZIKV infection was associated with early immune activation in both the peripheral blood and the CSF, but largely normalized by day 28 PI, with the exception of CSF CD8 T cell activation.

Hematoxylin and eosin-stained slides from the basal ganglia and parietal areas of each animal were reviewed by a board-certified veterinary pathologist. These sections were chosen as they represent superficial and deep parts of the brain. No pathological findings were observed.

\section{Neurocognitive impairment post-ZIKV infection}

Pre-infection CANTAB performance for each animal was established as the mean of the scores from the last 4 sessions of assessment prior to ZIKV inoculation (Additional file 2: Table S1). Median (IQR) of the pre-infection scores for all 8 animals were $80.48 \%$ (72.01-88.13) for MOT accuracy, $69.38 \%$ (49.53-82.97) for SOSS accuracy, 71.25 tasks (68.25-74.75) for the number of MOT performed within $10 \mathrm{~min}$ and $6.54 \mathrm{~min}(6.33-7.25)$ for the time required to complete 40 SOSS tasks.

To assess changes post-infection, individualized Z-scores (number of SD below or above the pre-infection mean) were generated for each animal at each assessment post-ZIKV inoculation (Fig. 5A). Impairments defined as $>2.5$ SD change were identified in 7 of 8 animals (Fig. 5B). Interestingly, female animals displayed more impairments (Fig. 5B); although this may be explained by learning style and performance approach rather than impairment per se. Importantly, 

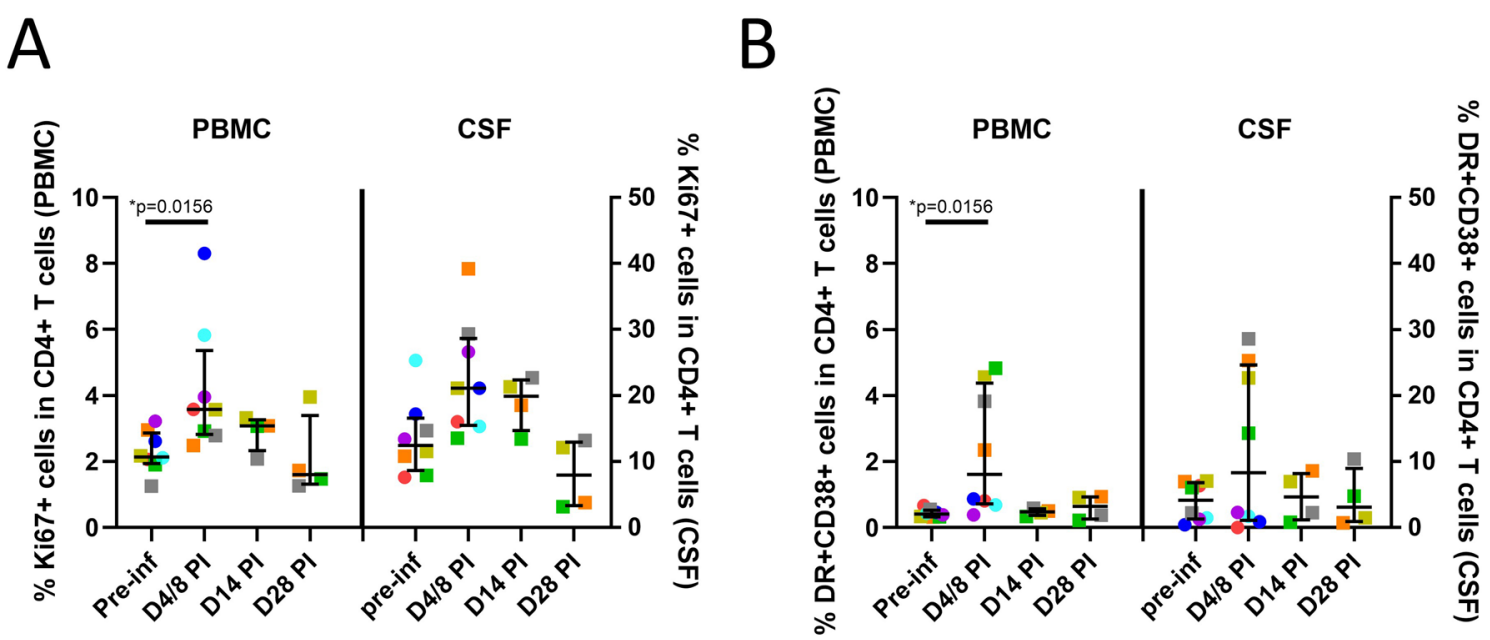

C
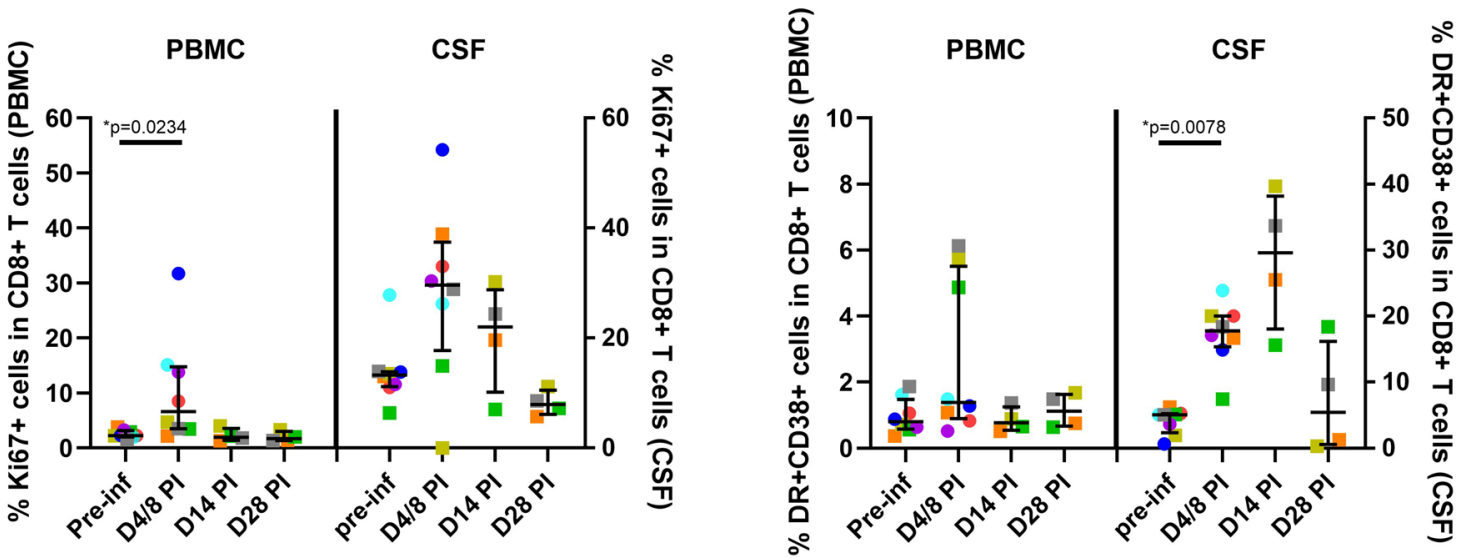

Fig. 4 Cellular markers of immune activation. Increases in cellular markers of immune activation were identified in CD4 and CD8 T cells in the peripheral blood and in CD8 T cells in the CSF. Percentages of Ki67 + cells $(\mathbf{A})$ and HLA-DR + CD38 + (B) in CD4 T cells and percentages of $\mathrm{Ki} 67+$ cells $(\mathbf{C})$ and HLA-DR $+\mathrm{CD} 38+$ (D) in CD8 T cells are shown. Each color represents data from individual animals as listed in Fig. 1B. ${ }^{*} P$ values were based on early post-inoculation (PI) results from all 8 animals (Late group, $n=4$ at day 4 PI, squares and Early group, $n=4$ at day 8 Pl, circles)

impairment in SOSS accuracy followed the peak of CSF CD8 $\mathrm{T}$ cell activation at day $14 \mathrm{PI}$ in 3 of 4 animals in the Late group (Fig. 5C), suggesting a potential link between neuroinflammation and neurocognitive impairment. The correlation is not statistically significant and larger experiments would be needed for additional validation of this observation.

On the modified Brinkman Board, all animals retrieved all raisins from the two boards in all assessments. No slowing was noted in the majority (6 of 8 ) of animals (Fig. 6). Animal R1301 at day 2 PI showed a marked

(See figure on next page.)

Fig. 5 Neurocognitive outcome as assessed by the Cambridge Neuropsychological Test Automated Battery (CANTAB). Individualized Z-scores (number of SD below or above the pre-infection mean) were generated for each animal at each assessment post-ZIKV inoculation (A). Impairment (shaded in red) is defined as > 2.5 SD reduction in accuracy for both Motor Screening Task (MOT) and Self-Ordered Spatial Search (SOSS), > 2.5 SD reduction in the number of MOT performed within $10 \mathrm{~min}$ or $>2.5$ SD increase in time to complete 40 SOSS tasks. Sex, age, timing of occurrence of and the number of impairments recorded are listed for each individual animal (B). ${ }^{*}$ Indicates the two animals that had detectable ZIKV RNA in the brain. Impairment on SOSS accuracy (filled symbols) followed the peaking of CSF HLA-DR+CD38+CD8 T cells (open symbols) in 3 of 4 animals in the Late group $(\mathbf{C})$. Each color represents data from individual animals as listed in Fig. 1B, animals in the early group are represented by circles and the late group by squares 
A
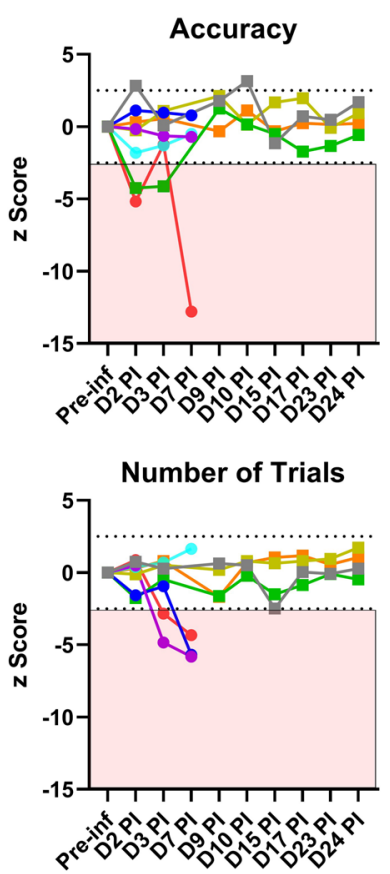
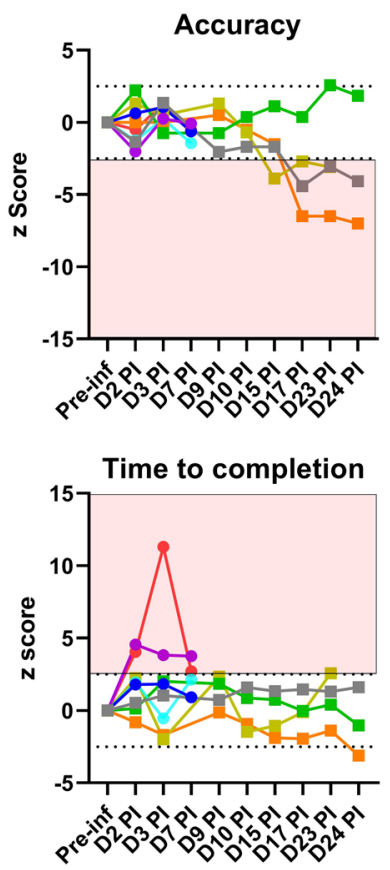

B

\begin{tabular}{|c|c|c|c|c|c|c|c|}
\hline & Sex & Age & \begin{tabular}{|l|} 
Motor Task \\
Accuracy (\%)
\end{tabular} & $\begin{array}{c}\text { Motor Task \# } \\
\text { of trials ( } n \text { ) }\end{array}$ & $\begin{array}{c}\text { SOSS } \\
\text { Accuracy (\%) }\end{array}$ & $\begin{array}{c}\text { SOSS Time to } \\
\text { completion (mins) }\end{array}$ & $\begin{array}{c}\text { \# of } \\
\text { Impairments (n) }\end{array}$ \\
\hline R1226 & $F$ & 7 & D2, D7 & D3, D7 & & D2, D3, D7 & 7 \\
\hline${ }^{*} \mathrm{R} 1435$ & $\mathbf{F}$ & 5 & & D3, D7 & & D2, D3, D7 & 5 \\
\hline R1325 & $F$ & 6 & D2, D3 & & & & 1 \\
\hline R1238 & $M$ & 7 & & & D17, D23, D24 & & 3 \\
\hline R1424 & $M$ & 5 & & D7 & & & 1 \\
\hline R1502 & $M$ & 5 & & & D17, D23, D24 & & 3 \\
\hline R1335 & M & 6 & & & & & 0 \\
\hline
\end{tabular}

C

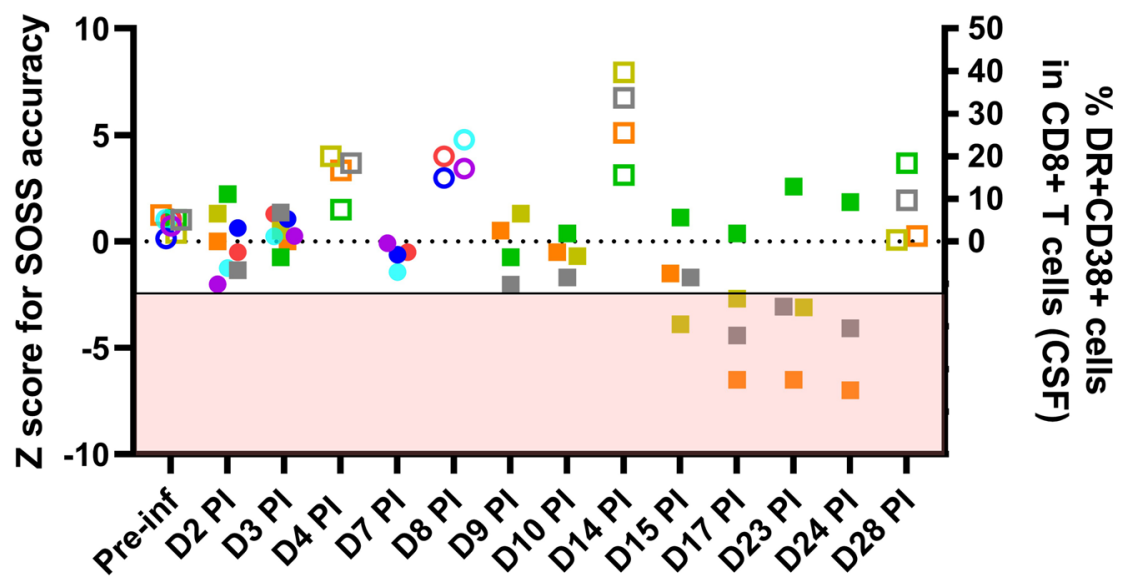

Fig. 5 (See legend on previous page.) 


\section{Modified Brinkman Board}
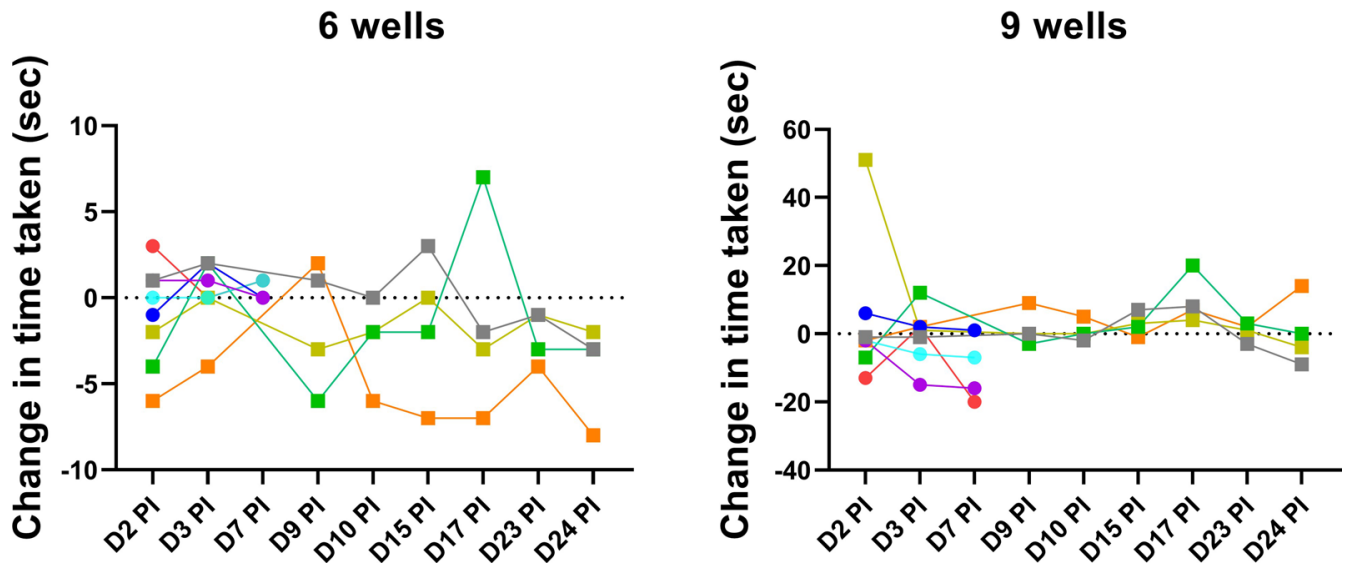

Fig. 6 Fine motor assessments on Brinkman Board. All animals retrieved all raisins ( 6 and 9 ) from the boards in all assessments. Each color represents data from individual animals as listed in Fig. 1B, animals in the early group are represented by circles and the late group by squares. Animal R1301 (yellow) showed marked increase in time to complete the 9-well board that was not mirrored in the 6-well board. Animal R1325 (green) showed increase in time to complete both 6- and 9-well boards at day 17 post-infection

increase in time to complete the more complex board with 9 wells, but that was not mirrored in the more simple board with 6 wells in the same test session. Animal R1325 showed an increase in time to complete the simple and complex boards at day 17 PI however, no impairment on CANTAB testing was noted on that day. Thus, these findings suggest that post-infection motor performance was unaffected as assessed by the modified Brinkman Board.

\section{Discussion}

Though not entirely faithful to human disease, NHP models of ZIKV infection have been widely used as they recapitulate many key clinical findings in humans, including rapid control of acute viremia, prolonged viral shedding and fetal pathology after infection in pregnant female animals $[28,59-61]$. To our knowledge, this is the first study to utilize adult rhesus macaques to evaluate the neurocognitive impact of ZIKV infection.

Rhesus macaque model of adult ZIKV infection has been well characterized. Animals are infected with ZIKV via subcutaneous inoculation at doses ranging from $10^{3}$ to $10^{6} \mathrm{PFU}$ [59-64]. ZIKV is detectable in the peripheral blood at day $1 \mathrm{PI}$, peaks rapidly with plasma viral load of around 5-7 $\log _{10}$ RNA copies/mL and then becoming undetectable at 5-10 days PI [59-63]. Sporadic and lower levels of ZIKV is usually observed in urine, genital secretions and saliva. The presence of virus in tissues including lymphoid, CNS and reproductive tissues can be more persistent, lasting weeks to months $[60,63,64]$. Histopathological findings in tissues in adult infection have been variable, ranging from no abnormalities to focal lymphocytic infiltration $[64,65]$.

Adult ZIKV infection is associated with immune activation with upregulation of cellular markers, including CD69, Ki67 and increases insoluble markers, including MCP-1, IL-2, IL-15, vascular endothelial growth factor (VEGF) and IL-10 in the first few days post-infection [60, 61, 63, 64]. ZIKV-specific binding and neutralizing antibodies emerges at 1 week PI and ZIKV-specific cellular responses soon follows, peaking at around 4 weeks PI [60, 61, 63-65].

Our adult rhesus macaque model of ZIKV infection showed post-infection characteristics that are novel, but also are consistent with the literature. We detected plasma ZIKV RNA at day one after virus inoculation, followed by an early peak and then clearance by 7 to 10 days [59-63] as well as persistence in lymphoid tissue $[60,63,64]$. We were, however, unable to detect ZIKV RNA in the CSF but detected ZIKV RNA in the brains of 2 of 8 animals. Although some studies have documented ZIKV RNA in the CSF in approximately half of the infected rhesus macaques [59-61, 63], the absence of detectable ZIKV RNA in the CSF has also been reported [30, 64, 65]. Our findings support the variability of host responses to ZIKV infection that may be related to viral and/or host risk and protective factors.

In this study, there were transient increases in cellular and soluble markers of immune activation in the peripheral blood, consistent with prior publications [60, 61, 
$63,64]$. Soluble markers of immune activation normalized in the CSF by day 14 post-infection, however, CD8 $\mathrm{T}$ cell activation remained elevated in 2 of 4 animals at day 28 PI. There is a dearth of data describing biomarkers of immune activation in the CSF and, as such, the finding of cellular activation 4 weeks PI is novel. A study with longer follow-up will be required to determine if cellular activation persists and assess its potential impact on long-term neurocognitive performance.

The most unique and significant finding is the identification of neurocognitive impairments ( $>2.5$ SD change) in 7 of 8 animals utilizing the Monkey CANTAB, which has been adapted from a human neuropsychological testing battery. Impairment in SOSS accuracy followed the peaking of CD8 $\mathrm{T}$ cell activation at day $14 \mathrm{PI}$ in 3 of 4 animals in the Late group. Studies in other disease models have shown that both experimentally induced and naturally occurring upper respiratory tract illnesses (URTIs) can influence mood and performance [66, 67]. Furthermore, the effects of influenza on performance can be mimicked by administrations of alpha interferon [68], suggesting that immune activation associated with viral infections can impact cognitive performance. These observations would need to be confirmed in a study with larger number of animals and longer follow-up.

The absence of uninfected controls is a potential limitation of this study. However, the study leveraged the methodological strengths of a longitudinal model in which individual animals served as their own control. This approach yielded statistically significant changes in immune responses in blood and CSF post-infection when compared with samples from the same animal pre-infection. In this study, we were unable to delineate whether the neurocognitive impairment was secondary to the direct effect of ZIKV infection or systemic immune activation. As such, the performance on CANTAB may potentially be confounded by a lack of engagement due to feeling unwell. However, the consistent retrieval of all raisins and the absence of simultaneous slowing on the Brinkman Board and impairments on CANTAB made that less likely.

NHP models are useful in the study of viral neuropathogenesis as they are closely related to humans, especially with respect to brain pathology, which is typically difficult to investigate in humans. To our knowledge, this is the first report where there is concomitant evaluation of the impact of Zika virus infection in adult rhesus macaques on soluble and cellular markers of immune activation in the CSF and assessment of neurocognition. Neurocognitive evaluation by CANTAB in NHP permits translation into humans as the instrument utilizes a cross-species cognitive test battery. This method can be applied to a diverse range of infectious as well as non-infectious conditions where there is reasonable clinicopathologic correlation between NHP models and clinical disease in humans.

\section{Conclusions}

In summary, Zika virus infection in adult rhesus macaques was associated with transient plasma viremia and immune activation in the peripheral blood and CSF. Importantly, neurocognitive impairment was identified in the majority of animals. The co-occurrence of systemic and neuro-immune perturbations and neurocognitive impairment establishes the utility of this model to further study the impacts of neuroinflammation on neurobehavior in rhesus macaques.

\section{Abbreviations}

ZIKV: Zika virus; CANTAB: Cambridge neuropsychological test automated battery; CSF: Cerebral spinal fluid; PI: Post-inoculation; DENV: Dengue virus; YFV:

Yellow fever virus; JEV: Japanese encephalitis virus; WNV: West Nile virus; TBEV: Tick-borne encephalitis virus; NHP: Nonhuman primate; AFRIMS: Armed Forces Research Institute of Medical Sciences; MOT: Motor screening task; SOSS: Self-Ordered Spatial Search; HAl: Hemagglutination inhibition; MEM: Minimum Essential Media; RT: Room temperature; PBMC: Peripheral blood mononuclear cells; DPBS: Dulbecco's phosphate buffered saline; SD: Standard deviation; URTIs: Upper respiratory tract illnesses.

\section{Supplementary Information}

The online version contains supplementary material available at https://doi. org/10.1186/s12974-022-02402-4.

Additional file 1: Fig. S1. Monkey CANTAB Intellistation with Pellet Reward training procedures.

Additional file 2: Table S1. Pre-infection Neurocognitive Performance.

\section{Acknowledgements}

We would like to thank Prof. Mark Tuszynski and his lab for sharing the design and specification as well as techniques around the administration of and interpretation of results from the Modified Brinkman Board. We would like to thank Dr. Rafael De La Barrera for the provision of ZIKV PRVABC59.

\section{Disclaimer}

The views expressed are those of the authors and should not be construed to represent the positions of the U.S. Army, the Department of Defense, or the Henry M. Jackson Foundation for the Advancement of Military Medicine, Inc.

\section{Authors' contributions}

DCH designed research, performed research, analyzed data, wrote the first draft of the paper, edited the paper. KC performed research, analyzed data, edited the paper and wrote the paper. MJC designed research, analyzed data, edited the paper, and wrote the paper. TH, DI, AS, RI, DS, PN, and JS performed research, analyzed data, edited the paper, and wrote the paper. YPN, CK and MR performed research, analyzed data and wrote the paper. SF, LCN, NLM, and KM designed research and edited the paper. RP designed research, contributed unpublished reagents/analytic tools and edited the paper. LLR designed research, performed research, and edited the paper. SV designed research, edited the paper, and wrote the paper. All authors read and approved the final manuscript.

\section{Funding}

This work was supported by a cooperative agreement (W81XWH-18-2-0040) between the Henry M. Jackson Foundation for the Advancement of Military Medicine, Inc., (HJF) and the U.S. Department of Defense (DoD). 


\section{Availability of data and materials}

The data generated or analyzed during this study are included in this published article.

\section{Declarations}

\section{Ethics approval and consent to participate}

The protocol was approved by the AFRIMS Institutional Animal Care and Use Committee. Research was conducted under an approved animal use protocol in an AAALAC International-accredited facility in compliance with the Animal Welfare Act and other federal statutes and regulations relating to animals and experiments involving animals and adheres to principles stated in the Guide for the Care and Use of Laboratory Animals, NRC Publication, 2011 edition.

\section{Consent for publication}

Not applicable.

\section{Competing interests}

The authors declare no competing financial interests.

\section{Author details}

${ }^{1}$ US Military HIV Research Program, Walter Reed Army Institute of Research, Silver Spring, MD 20910, USA. ${ }^{2}$ Armed Forces Research Institute of Medical Sciences, Bangkok 10400, Thailand. ${ }^{3}$ Henry M. Jackson Foundation for the Advancement of Military Medicine, Inc, Bethesda, MD 20817, USA. ${ }^{4}$ Division of Infectious Diseases, Department of Medicine, Weill Cornell Medicine, New York, USA. ${ }^{5}$ Feil Family Brain \& Mind Research Institute, Weill Cornell Medicine, New York, NY 10021, USA. ${ }^{6}$ Missouri Institute of Mental Health, University of Missouri, St. Louis, MO 63143, USA. ${ }^{7}$ Center for Infectious Diseases Research, Walter Reed Army Institute of Research, Silver Spring, MD 20910, USA. ${ }^{8}$ Emerging Infectious Disease Branch, Walter Reed Army Institute of Research, Silver Spring, MD 20910, USA.

Received: 26 July 2021 Accepted: 24 January 2022

Published online: 07 February 2022

\section{References}

1. Chong HY, Leow CY, Abdul Majeed AB, Leow CH. Flavivirus infection-A review of immunopathogenesis, immunological response, and immunodiagnosis. Virus Res. 2019;274:197770.

2. Moore CA, Staples JE, Dobyns WB, Pessoa A, Ventura CV, Fonseca EB, Ribeiro EM, Ventura LO, Neto NN, Arena JF, Rasmussen SA. Characterizing the pattern of anomalies in congenital zika syndrome for pediatric clinicians. JAMA Pediatr. 2017;171:288-95.

3. de Oliveira Garcia MH. Zika: the continuing threat. Bull World Health Organ. 2019;97:6-7.

4. Mlakar J, Korva M, Tul N, Popovic M, Poljsak-Prijatelj M, Mraz J, Kolenc M, Resman Rus K, Vesnaver VipotnikT, Fabjan Vodusek V, et al. Zika virus associated with microcephaly. N Engl J Med. 2016;374:951-8.

5. Driggers RW, Ho CY, Korhonen EM, Kuivanen S, Jaaskelainen AJ, Smura T, Rosenberg A, Hill DA, DeBiasi RL, Vezina G, et al. Zika virus infection with prolonged maternal viremia and fetal brain abnormalities. N Engl J Med. 2016:374:2142-51.

6. Martines RB, Bhatnagar J, Keating MK, Silva-Flannery L, Muehlenbachs A, Gary J, Goldsmith C, Hale G, Ritter J, Rollin D, et al. Notes from the field: evidence of zika virus infection in brain and placental tissues from two congenitally infected newborns and two fetal losses-Brazil, 2015. MMWR Morb Mortal Wkly Rep. 2016;65:159-60.

7. Tang H, Hammack C, Ogden SC, Wen Z, Qian X, Li Y, Yao B, Shin J, Zhang $F$, Lee EM, et al. Zika virus infects human cortical neural progenitors and attenuates their growth. Cell Stem Cell. 2016;18:587-90.

8. Souza BS, Sampaio GL, Pereira CS, Campos GS, Sardi SI, Freitas LA, Figueira CP, Paredes BD, Nonaka CK, Azevedo CM, et al. Zika virus infection induces mitosis abnormalities and apoptotic cell death of human neural progenitor cells. Sci Rep. 2016;6:39775.

9. Schuler-Faccini L, Ribeiro EM, Feitosa IM, Horovitz DD, Cavalcanti DP, Pessoa A, Doriqui MJ, Neri JI, Neto JM, Wanderley HY, et al. Possible association between zika virus infection and microcephaly - Brazil, 2015. MMWR Morb Mortal Wkly Rep. 2016;65:59-62.

10. Rasmussen SA, Jamieson DJ, Honein MA, Petersen LR. Zika virus and birth defects-reviewing the evidence for causality. N Engl J Med. 2016;374:1981-7.

11. Krauer F, Riesen M, Reveiz L, Oladapo OT, Martinez-Vega R, Porgo TV, Haefliger A, Broutet NJ, Low N. Group WHOZCW: Zika virus infection as a cause of congenital brain abnormalities and guillain-barre syndrome: systematic review. PLoS Med. 2017;14:e1002203.

12. Aragao M, Holanda AC, Brainer-Lima AM, Petribu NCL, Castillo M, van der Linden V, Serpa SC, Tenorio AG, Travassos PTC, Cordeiro MT, et al. Nonmicrocephalic infants with congenital zika syndrome suspected only after neuroimaging evaluation compared with those with microcephaly at birth and postnatally: how large is the Zika Virus "Iceberg"? AJNR Am J Neuroradiol. 2017;38:1427-34.

13. Cranston JS, Tiene SF, Nielsen-Saines K, Vasconcelos Z, Pone MV, Pone S, Zin A, Salles TS, Pereira JP Jr, Orofino D, et al. Association between antenatal exposure to Zika Virus and anatomical and neurodevelopmental abnormalities in children. JAMA Netw Open. 2020;3:e209303.

14. Stringer EM, Martinez E, Blette B, Toval Ruiz CE, Boivin M, Zepeda O, Stringer JSA, Morales M, Ortiz-Pujols S, Familiar I, et al. Neurodevelopmental outcomes of children following in utero exposure to zika in Nicaragua. Clin Infect Dis. 2021;72:e146-53.

15. Mulkey SB, Arroyave-Wessel M, Peyton C, Bulas DI, Fourzali Y, Jiang J, Russo S, McCarter R, Msall ME, du Plessis AJ, et al. Neurodevelopmental abnormalities in children with in utero zika virus exposure without congenital Zika Syndrome. JAMA Pediatr. 2020;174:269-76.

16. Musso D, Nhan T, Robin E, Roche C, Bierlaire D, Zisou K, Shan Yan A, Cao-Lormeau VM. Broult J: Potential for Zika virus transmission through blood transfusion demonstrated during an outbreak in French Polynesia, November 2013 to February 2014. Euro Surveill. 2013;2014:19.

17. Duffy MR, Chen TH, Hancock WT, Powers AM, Kool JL, Lanciotti RS, Pretrick M, Marfel M, Holzbauer S, Dubray C, et al. Zika virus outbreak on Yap Island, Federated States of Micronesia. N Engl J Med. 2009:360:2536-43.

18. Brasil P, Pereira JP Jr, Moreira ME, Ribeiro Nogueira RM, Damasceno L, Wakimoto M, Rabello RS, Valderramos SG, Halai UA, Salles TS, et al. Zika Virus infection in pregnant women in Rio de Janeiro. N Engl J Med. 2016;375:2321-34.

19. Musso D, Gubler DJ. Zika Virus. Clin Microbiol Rev. 2016;29:487-524.

20. Cao-Lormeau VM, Blake A, Mons S, Lastere S, Roche C, Vanhomwegen J, Dub T, Baudouin L, Teissier A, Larre P, et al. Guillain-Barre Syndrome outbreak associated with Zika virus infection in French Polynesia: a case-control study. Lancet. 2016;387:1531-9.

21. Dos Santos T, Rodriguez A, Almiron M, Sanhueza A, Ramon P, de Oliveira WK, Coelho GE, Badaro R, Cortez J, Ospina M, et al. Zika Virus and the guillain-barre syndrome - case series from seven countries. N Engl J Med. 2016;375:1598-601.

22. Carteaux G, Maquart M, Bedet A, Contou D, Brugieres P, Fourati S. Cleret de Langavant L, de Broucker T, Brun-Buisson C, Leparc-Goffart I, Mekontso Dessap A: Zika Virus Associated with Meningoencephalitis. N Engl J Med. 2016;374:1595-6.

23. Hughes BW, Addanki KC, Sriskanda AN, McLean E, Bagasra O. Infectivity of immature neurons to zika virus: a link to congenital zika syndrome. EBioMedicine. 2016;10:65-70.

24. Zucker J, Neu N, Chiriboga CA, Hinton VJ, Leonardo M, Sheikh A, Thakur K. Zika Virus-associated cognitive impairment in adolescent, 2016. Emerg Infect Dis. 2017;23:1047-8.

25. Ohki CMY, Benazzato C, Russo FB, Beltrao-Braga PCB. Developing animal models of Zika virus infection for novel drug discovery. Expert Opin Drug Discov. 2019;14:577-89.

26. Dick GW. Zika virus. II. Pathogenicity and physical properties. Trans R Soc Trop Med Hyg. 1952;46:521-34.

27. Adams Waldorf KM, Nelson BR, Stencel-Baerenwald JE, Studholme C, Kapur RP, Armistead B, Walker CL, Merillat S, Vornhagen J, Tisoncik-Go $J$, et al. Congenital Zika virus infection as a silent pathology with loss of neurogenic output in the fetal brain. Nat Med. 2018;24:368-74.

28. Adams Waldorf KM, Stencel-Baerenwald JE, Kapur RP, Studholme C, Boldenow E, Vornhagen J, Baldessari A, Dighe MK, Thiel J, Merillat S, et al. Fetal brain lesions after subcutaneous inoculation of Zika virus in a pregnant nonhuman primate. Nat Med. 2016;22:1256-9. 
29. Nguyen SM, Antony KM, Dudley DM, Kohn S, Simmons HA, Wolfe B, Salamat MS, Teixeira LBC, Wiepz GJ, Thoong TH, et al. Highly efficient maternal-fetal Zika virus transmission in pregnant rhesus macaques. PLoS Pathog. 2017;13:e1006378.

30. Mavigner M, Raper J, Kovacs-Balint Z, Gumber S, O'Neal JT, Bhaumik SK, Zhang X, Habib J, Mattingly C, McDonald CE, et al. Postnatal Zika virus infection is associated with persistent abnormalities in brain structure, function, and behavior in infant macaques. Sci Transl Med. 2018;10:89.

31. Sahakian BJ, Owen AM. Computerized assessment in neuropsychiatry using CANTAB: discussion paper. J R Soc Med. 1992;85:399-402.

32. Kangas BD, Bergman J. Touchscreen technology in the study of cognition-related behavior. Behav Pharmacol. 2017;28:623-9.

33. Brinkman J, Kuypers HG. Cerebral control of contralateral and ipsilateral arm, hand and finger movements in the split-brain rhesus monkey. Brain. 1973;96:653-74.

34. Aslam RW, Bates V, Dundar Y, Hounsome J, Richardson M, Krishan A, Dickson R, Boland A, Fisher J, Robinson L, Sikdar S. A systematic review of the diagnostic accuracy of automated tests for cognitive impairment. Int J Geriatr Psychiatry. 2018;33:561-75.

35. Nagahara AH, Bernot T, Tuszynski MH. Age-related cognitive deficits in rhesus monkeys mirror human deficits on an automated test battery. Neurobiol Aging. 2010;31:1020-31.

36. National Research Council. Guide for the care and use of laboratory animals. 2011.

37. Luciana M, Nelson CA. The functional emergence of prefrontally-guided working memory systems in four-to eight-year-old children. Neuropsychologia. 1998;36:273-93.

38. Strike SC, Carlisle A, Gibson EL, Dyall SC. A high omega-3 fatty acid multinutrient supplement benefits cognition and mobility in older women: a randomized, double-blind, placebo-controlled pilot study. J Gerontol Series A. 2016;71:236-42.

39. Abbott RA, Skirrow C, Jokisch M, Timmers M, Streffer J, van Nueten L, Krams M, Winkler A, Pundt N, Nathan PJ. Normative data from linear and nonlinear quantile regression in CANTAB: Cognition in mid-to-late life in an epidemiological sample. Alzheimer's Dementia. 2019;11:36-44.

40. Weed MR, Taffe MA, Polis I, Roberts AC, Robbins TW, Koob GF, Bloom FE, Gold LH. Performance norms for a rhesus monkey neuropsychological testing battery: acquisition and long-term performance. Cogn Brain Res. 1999;8:185-201.

41. Lawrence AD, Sahakian BJ, Hodges JR, Rosser AE, Lange KW, Robbins TW. Executive and mnemonic functions in early Huntington's disease. Brain. 1996;119:1633-45.

42. Owen A, James M, Leigh P, Summers B, Marsden C. Fronto-striatal cognitive deficits at different stages of Parkinson's disease. Brain. 1992;115:1727-51.

43. Stip E, Sepehry AA, Prouteau A, Briand C, Nicole L, Lalonde P, Lesage A. Cognitive discernible factors between schizophrenia and schizoaffective disorder. Brain Cogn. 2005;59:292-5.

44. Weed MR, Gold LH, Polis I, Koob GF, Fox HS, Taffe MA. Impaired performance on a rhesus monkey neuropsychological testing battery following simian immunodeficiency virus infection. AIDS Res Hum Retroviruses. 2004;20:77-89.

45. Gold LH, Fox HS, Henriksen SJ, Buchmeier MJ, Weed MR, Taffe MA, Huitrón-Resendiz S, Horn TF, Bloom FE. Longitudinal analysis of behavioral, neurophysiological, viral and immunological effects of SIV infection in rhesus monkeys. J Med Primatol. 1998;27:104-12.

46. D'Souza DC, Braley G, Blaise R, Vendetti M, Oliver S, Pittman B, Ranganathan M, Bhakta S, Zimolo Z, Cooper T. Effects of haloperidol on the behavioral, subjective, cognitive, motor, and neuroendocrine effects of $\triangle-9$ tetrahydrocannabinol in humans. Psychopharmacology. 2008;198:587-603.

47. Mehta MA, Sahakian BJ, Robbins TW. Comparative psychopharmacology of methylphenidate and related drugs in human volunteers, patients with ADHD, and experimental animals. 2001.

48. Taffe MA, Davis SA, Gutierrez T, Gold LH. Ketamine impairs multiple cognitive domains in rhesus monkeys. Drug Alcohol Depend. 2002;68:175-87.

49. Weed MR, Gold LH. The effects of dopaminergic agents on reaction time in rhesus monkeys. Psychopharmacology. 1998;137:33-42.

50. Freund P, Schmidlin E, Wannier T, Bloch J, Mir A, Schwab ME, Rouiller EM. Anti-Nogo-A antibody treatment promotes recovery of manual dexterity after unilateral cervical lesion in adult primates-re-examination and extension of behavioral data. Eur J Neurosci. 2009;29:983-96.
51. Rosenzweig ES, Salegio EA, Liang JJ, Weber JL, Weinholtz CA, Brock JH, Moseanko R, Hawbecker S, Pender R, Cruzen CL, et al. Chondroitinase improves anatomical and functional outcomes after primate spinal cord injury. Nat Neurosci. 2019;22:1269-75.

52. Larocca RA, Abbink P, Peron JP, Zanotto PM, lampietro MJ, BadamchiZadeh A, Boyd M, Ng'ang'a D, Kirilova M, Nityanandam R, et al. Vaccine protection against Zika virus from Brazil. Nature. 2016;536:474-8.

53. Buathong R, Hermann L, Thaisomboonsuk B, Rutvisuttinunt W, Klungthong C, Chinnawirotpisan P, Manasatienkij W, Nisalak A, Fernandez S, Yoon IK, et al. Detection of Zika Virus Infection in Thailand, 2012-2014. Am J Trop Med Hyg. 2015;93:380-3.

54. Sirikajornpan K, Suntarattiwong P, Suwanpakdee D, Tabprasit S, Buddhari D, Thaisomboonsuk B, Klungthong C, Poolpanichupatam Y, Buathong R, Srikiatkhachorn A, et al. Standardization and Evaluation of an Anti-ZIKV IgM ELISA Assay for the Serological Diagnosis of Zika Virus Infection. Am J Trop Med Hygiene Accepted.

55. Lanciotti RS, Kosoy OL, Laven JJ, Velez JO, Lambert AJ, Johnson AJ, Stanfield SM, Duffy MR. Genetic and serologic properties of Zika virus associated with an epidemic, Yap State, Micronesia, 2007. Emerg Infect Dis. 2008;14:1232-9.

56. Colombo TE, Terzian ACB, Junior JPA, Parreira R, Cabrera EMS, Santos I, Reis AFN, Costa FR, Cruz L, Rombola PL, Nogueira ML. Zika detection: comparison of methodologies. Braz J Microbiol. 2018;49:144-7.

57. Waggoner JJ, Pinsky BA. Zika Virus: diagnostics for an emerging pandemic threat. J Clin Microbiol. 2016;54:860-7.

58. Hsu DC, Sunyakumthorn P, Wegner M, Schuetz A, Silsorn D, Estes JD, Deleage C, Tomusange K, Lakhashe SK, Ruprecht RM, et al. Central nervous system inflammation and infection during early, nonaccelerated simian-human immunodeficiency virus infection in rhesus macaques. J Virol. 2018;92:e00222-e1218.

59. Abbink P, Larocca RA, De La Barrera RA, Bricault CA, Moseley ET, Boyd M, Kirilova M, Li Z, Ng'ang'a D, Nanayakkara O, et al. Protective efficacy of multiple vaccine platforms against Zika virus challenge in rhesus monkeys. Science. 2016;353:1129-32.

60. Osuna CE, Lim SY, Deleage C, Griffin BD, Stein D, Schroeder LT, Omange RW, Best K, Luo M, Hraber PT, et al. Zika viral dynamics and shedding in rhesus and cynomolgus macaques. Nat Med. 2016;22:1448-55.

61. Dudley DM, Aliota MT, Mohr EL, Weiler AM, Lehrer-Brey G, Weisgrau KL, Mohns MS, Breitbach ME, Rasheed MN, Newman CM, et al. A rhesus macaque model of Asian-lineage Zika virus infection. Nat Commun. 2016;7:12204.

62. Abbink P, Larocca RA, Visitsunthorn K, Boyd M, De La Barrera RA, Gromowski GD, Kirilova M, Peterson R, Li Z, Nanayakkara O, et al. Durability and correlates of vaccine protection against Zika virus in rhesus monkeys. Sci Transl Med. 2017;9:e38.

63. Aid M, Abbink P, Larocca RA, Boyd M, Nityanandam R, Nanayakkara O, Martinot AJ, Moseley ET, Blass E, Borducchi EN, et al. Zika Virus Persistence in the Central Nervous System and Lymph Nodes of Rhesus Monkeys. Cell. 2017;169:610-20.

64. Hirsch AJ, Smith JL, Haese NN, Broeckel RM, Parkins CJ, Kreklywich C, DeFilippis VR, Denton M, Smith PP, Messer WB, et al. Zika Virus infection of rhesus macaques leads to viral persistence in multiple tissues. PLoS Pathog. 2017;13:e1006219.

65. Coffey LL, Pesavento PA, Keesler RI, Singapuri A, Watanabe J, Watanabe R, Yee J, Bliss-Moreau E, Cruzen C, Christe KL, et al. Zika Virus Tissue and Blood Compartmentalization in Acute Infection of Rhesus Macaques. PLoS ONE. 2017;12:e0171148.

66. Smith AP. Twenty-five years of research on the behavioural malaise associated with influenza and the common cold. Psychoneuroendocrinology. 2013;38:744-51.

67. Bucks RS, Gidron Y, Harris P, Teeling J, Wesnes KA, Perry VH. Selective effects of upper respiratory tract infection on cognition, mood and emotion processing: a prospective study. Brain Behav Immun. 2008;22:399-407.

68. Smith A, Tyrrell D, Coyle K, Higgins P. Effects of interferon alpha on performance in man: a preliminary report. Psychopharmacology. 1988;96:414-6.

\section{Publisher's Note}

Springer Nature remains neutral with regard to jurisdictional claims in published maps and institutional affiliations. 